\title{
Erratum to: Ethics and aesthetics of technologies
}

\author{
Arun Kumar Tripathi
}

Published online: 10 March 2010

(C) Springer-Verlag London Limited 2010

\section{Erratum to: AI \& Soc \\ DOI 10.1007/s00146-010-0265-7}

In Human-Computer Interaction research, several disciplines have come to give their contribution to the field, each with different emphases, traditions and views points. Daniel Fallman elaborates "early parts of cognitive psychology showed interest in the new field and stressed the application of models and theories of cognitive processes when designing the meeting between human and interface" (Fallman 2007). Human-Computer Interaction (HCI) is concerned with the design, implementation and evaluation of interactive computer-based systems, as well as with the multi-disciplinary study of various issues affecting this interaction. The aim of HCI is "to ensure the safety, utility, effectiveness, efficiency, accessibility and usability of such systems. In recent years, HCI has attracted considerable attention by the academic and research communities, as well as by the Information Society Technologies industry" (Stephanidis and Savidis 2001). The on-going paradigm shift towards a knowledge-intensive Information Society has brought about radical changes in the way people work and interact with each other and with information. Computermediated human activities undergo fundamental changes and new ones appear continuously, as new, intelligent, distributed, and highly interactive technological environments emerge, making available concurrent access to

The online version of the original article can be found under doi: 10.1007/s00146-010-0265-7.

\section{A. K. Tripathi $(\bowtie)$}

Department of Philosophy of Technology,

Institute for Philosophy,

Dresden University of Technology, Dresden, Germany

e-mail: arun.tripathi@waoe.org heterogeneous information sources and interpersonal communication. The progressive fusion of existing and emerging technologies is transforming the computer from a specialist's device into an information appliance. "This dynamic evolution is characterized by several dimensions of diversity that are intrinsic to the Information Society." These become evident when considering the broad range of user characteristics, the changing nature of human activities, the variety of contexts of use, the increasing availability and diversification of information, knowledge sources and services, the proliferation of diverse technological platforms, etc.

"Human-Computer Interaction plays a critical role in the context of the emerging Information Society, as citizens experience technology through their contact with the user interfaces of interactive products, applications and services. Therefore, it is important to ensure that user interfaces provide access and quality in use to all potential users, in all possible of contexts of use, and through a variety of technological platforms" (Tripathi 2005; Stephanidis 2007).

\section{References}

Fallman D (2007) Why research-oriented design isn't design-oriented research: on the tensions between design and research in an implicit design discipline. J Knowl Technol Policy. Special issue on design research, vol 20, no. 3, Springer, The Netherlands. doi: $10.1007 / \mathrm{s} 12130-007-9022-8$

Stephanidis C (ed) (2007) Universal access in human-computer interaction. Ambient interaction part II, HCII 2007, LNCS 4555, Springer

Stephanidis C, Savidis A (2001) Universal access in the information society: methods, tools, and interaction technologies. In: Universal access in the information society, vol 1, no. 1, pp 40-55

Tripathi AK (2005) Computers and the embodied nature of communication: Merleau-Ponty's new ontology of embodiment. Ubiquity 6(44) 